\title{
Fault Zone Drilling in the Backstop to the Mediterranean Ridge Accretionary Complex off Crete, Greece
}

\author{
by Achim Kopf and Marco Bohnhoff
}

doi:10.2204/iodp.sd.s01.14.2007

\section{Regional Geological Setting}

Scientific drilling and the installation of downhole seismic instrumentation to observe seismicity at a low-magnitude detection threshold are powerful tools to monitor densely populated areas in Southern Europe, such as the Athens metropolitan region, to minimize societal and environmental dangers, which millennia ago destroyed entire cultures, two of the seven wonders of the world (Colossus of Rhodes 224 BC, Lighthouse on Pharos 365 AD) and several historical sites in the circum-Mediterranean. The Eastern Mediterranean hosts one of the most prominent retreating convergent margins worldwide that was capable of generating $\mathrm{M}>8$ earthquakes (365 $\mathrm{AD}$, western Crete) and exhaustive volcanic eruptions (1650 BC, Santorini) in historic times.

The Hellenic Subduction Zone (HSZ) in the Eastern Mediterranean Sea represents a mature subduction zone where African crust is thrust (i.e., subducted) beneath Eurasia and where a wide backstop area of partly old accreted strata (marine), partly HP/LT rocks (the exhumed island of Crete as forearc high), an extensional submerged landward forearc (Cretan Sea), and a volcanic arc and backarc basin (Aegean Sea) evolved. The HSZ is an ideal natural laboratory

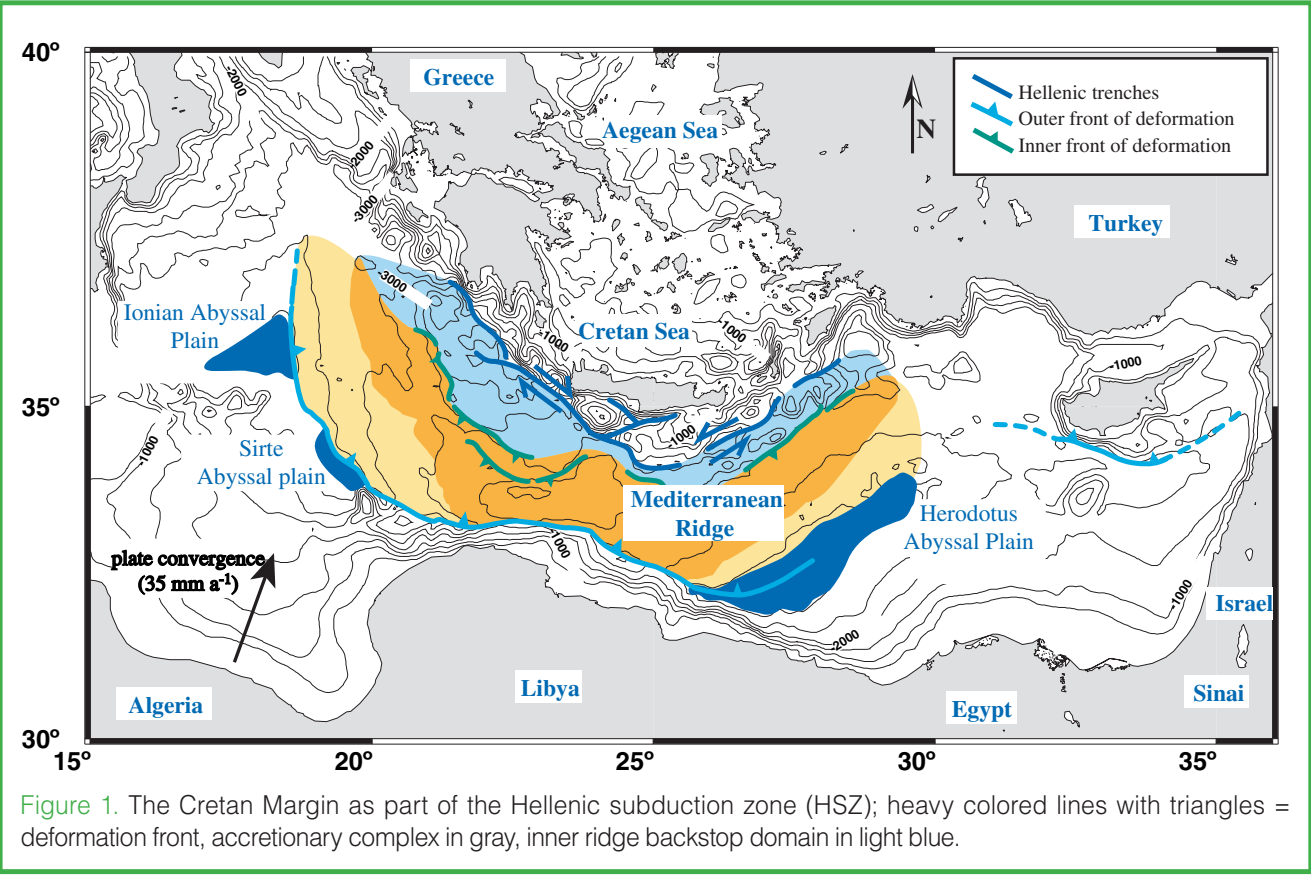

to study collisional processes which are well recorded over the past ca. 35 million years, including an intermittent stage of micro-continent collisions between about $30 \mathrm{Ma}$ and $20 \mathrm{Ma}$, followed by breakoff of the subducting slab, and incipient collision with the passive African margin today (Thomson et al., 1998). The island of Crete represents a horst structure developed within the last 5 million years in the central forearc, and it provides excellent onshore access to the internal structure of the forearc at various levels (for overall geodynamic situation in map view, see Fig. 1).

\section{Scientific Drilling}

An "amphibic" scientific drilling approach is planned for the HSZ, comprising a northern (International Continental Scientific Drilling Project (ICDP)-driven) and a southern (Integrated Ocean Drilling Program (IODP)-driven) domain. Having been kicked off at an ICDP workshop on Crete in 1998, proposals for backstop drilling in the Cretan Sea (ICDP), on Crete (ICDP), and in the Mediterranean Sea (IODP) were developed and later combined to an onshoreoffshore deep drilling transect along the HSZ (Fig. 2). With moderately deep marine drill sites (ca. $1 \mathrm{~km}$ depth) in the backstop region south of Crete, one continental 3-4-km-deep drill hole onshore Crete, and further ICDP (Glad800) offshore holes within the Cretan Sea (i.e., the forearc-backarc transitional zone) and the volcanic arc (i.e., the submerged Kolumbo volcano as part of the Santorini volcanic complex), we anticipate a substantial contribution to the understanding of earthquake hazard and mitigation, tectonic evolution, and rheology of active collision zones. In this paper, we focus on the marine drilling project where three drill sites are anticipated to penetrate active fault zones.

\section{Fault Zone Drilling in the Backstop}

Within ODP (Ocean Drilling Program) and its 


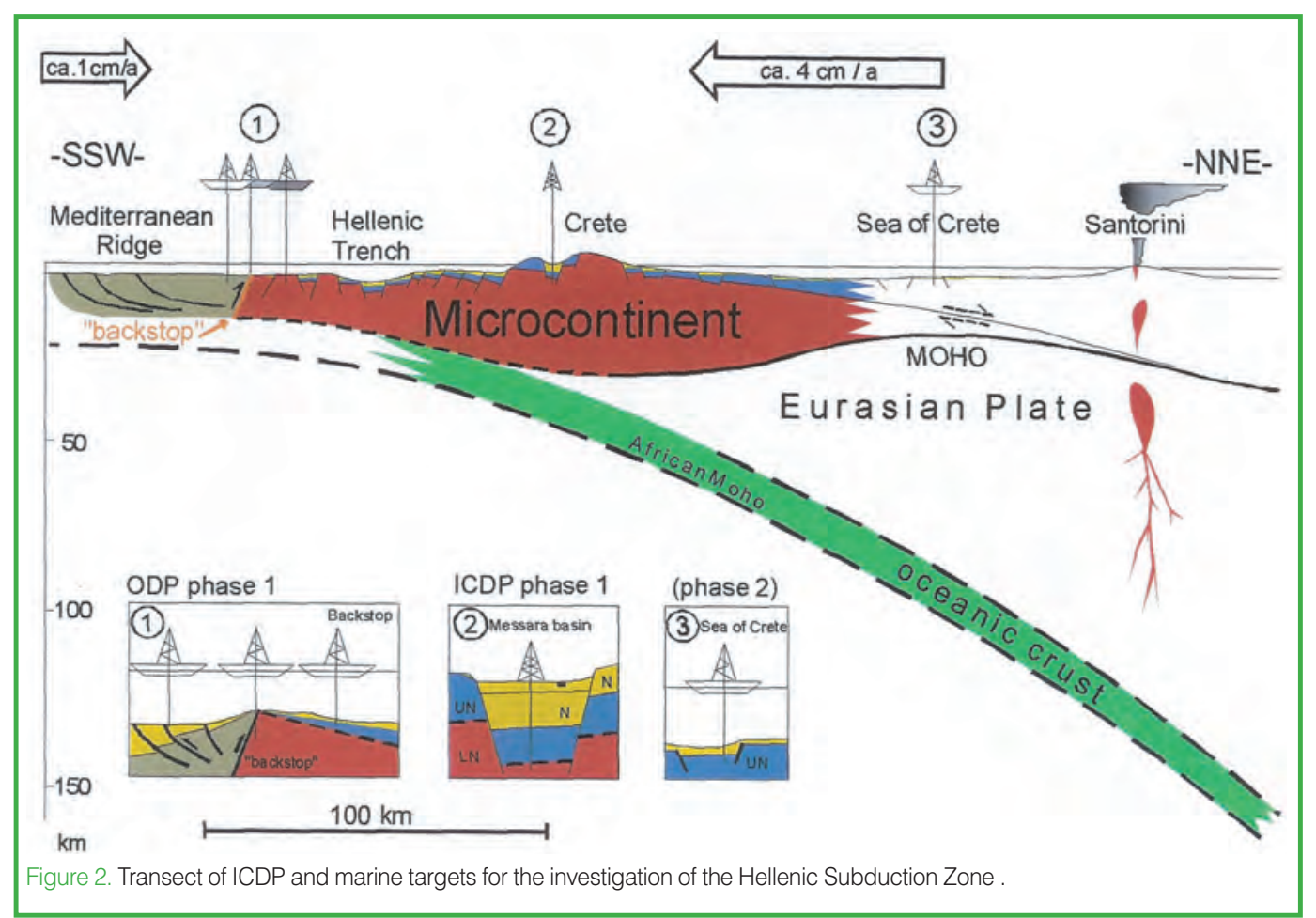

predecessor DSDP (Deep Sea Drilling Project), several convergent margins have been investigated; however, all these regions have in common that drilling focused entirely on the frontal portion of the forearc prism. Due to this shortcoming, Kopf et al. (1999) proposed to drill a transect of three sites south of the island of Crete (E Mediterranean) from the distal part of the Mediterranean Ridge accretionary prism (MedRidge) across its backstop. Following geophysical surveys and analog modeling, drilling a backstop (or buttress) setting is essential to elucidate fundamental deep fluid flow processes and deformation mechanisms within an accretionary prism and its buttress. Variability in fluid flux across the wedge to its buttress must influence fluid budgets of the accretionary complex, and earlier work attested that flux rates in the backstop domain exceed those near the toe of the accretionary complex (Kopf et al., 2001). The marine transect aims to illuminate (1) mass and fluid transfer at an accreting convergent margin, (2) the significance of spatial variability of fluids from mineral dehydration and diagenetic alteration at depth, and their interaction with the rock, and (3) their possible effect on seismicity. Each of the three 1-km-deep drill holes in the backstop domain will penetrate deep-seated thrusts and backthrust faults whose fluids act as windows down to several kilometers depth. Fluids will be indicative of enhanced dewatering reactions and possibly cause earthquake swarms in the area. Monitoring of fluidflow and pressure variations would have profound effects on the understanding of fluid budgets and global mass balances, and seismogenesis.

The three fault zones to be penetrated by ocean drilling are: (i) An active backthrust fault within the distal part of the accretionary complex, which is juxtaposed by a small $(1 \mathrm{~km}$ across) mud volcano;

(ii) The backthrust contact between the Inner Ridge backstop and the accretionary complex; and

(iii) A reverse fault in the higher Cretan submarine forearc, which separates the exhumed HP/LT units from the overlying thrust nappes forming the bulk part of the island of Crete.

Seismic reflection data suggest fluid migration and activity of each of these fault zones, the latter being the most exciting one since the former detachment fault plane will provide us a window to the depth of slab break off.

\section{References}

Kopf, A., Klaeschen, D., and Mascle, J., 2001. Extreme efficiency of mud volcanism in dewatering accretionary prisms. Earth Planet. Sci. Lett., 189(3-4):295-313, doi:10.1016/ S0012/821X(01)00278-3.

Kopf, A., Robertson, A.H.F., Screaton, E.J., Mascle, J., Parkes, R.J., Foucher, J.P., DeLange, G.J., Stöckhert, B., and Sakellariou, D., 1999. Backstop hydrogeology of a wide accretionary complex south of Crete, Eastern Mediterranean Sea. Full drilling proposal (\#555) for the Ocean Drilling Program, $25 \mathrm{p}$.

Thomson,S.N.,Stöckhert,B., andBrix,M.R.,1998.Thermochronology of the high-pressure metamorphic rocks of Crete, Greece: Implications for the speed of tectonic processes. Geology, 26:259-262, doi:10.1130/0091-7613(1998)026<0259;TOTH $\mathrm{PM}>2.3 . \mathrm{CO} ; 2$.

\section{Authors}

Achim Kopf, Research Center Ocean Margins (RCOM), University of Bremen, Leobener Strasse, 28359 Bremen, Germany, e-mail: akopf@uni-bremen.de.

Marco Bohnhoff, GeoForschungsZentrum Potsdam, Telegrafenberg D424, 14473 Potsdam, Germany. 